\title{
Violencias interseccionales y espiritualidades en la vida de mujeres mesoamericanas como problema teórico-práctico*
}

Recibido: 12 de octubre 2016

Revisado: 7 de diciembre 2016

Aprobado: 11 de julio 2017

\section{Dagoberto Nuñez Picado}

Costarricense. Investigador del campo axiológico

religioso del Centro de

Investigación en Cultura y

Desarrollo (CICDE) de la

Vicerrectoría de

Investigación de la

Universidad Estatal a

Distancia (UNED-Costa

Rica). Doctor en Educación

U-Lasalle, Máster en

Estudios Culturales

Centroamericanos (UNA, Costa Rica) Licenciado en

Teología (Escuela Ecuménica

de Ciencias de la Religión,

UNA) y Licenciado en

Ciencias de la Comunicación

(Universidad de Costa Rica).

Correo electrónico:

dnunez@uned.ac.cr

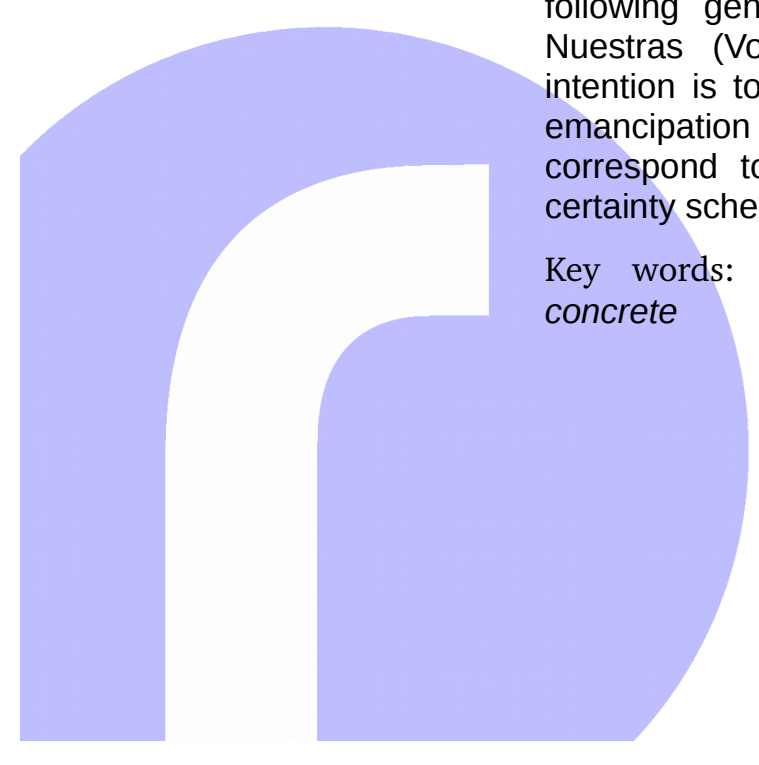

http://investiga.uned.ac.cr/rupturas/ (c) (1)(2) concreto concrete
Resumen: La articulación teoría-práctica puede ser comprendida desde la distinción que Herrera Flores establece entre "el otro generalizado" y "el otro concreto" para indicar que en el fondo lo teórico-práctico remite a comprensión de sujetos humanos encarnados socio-históricamente. Desde este enfoque, dicha articulación nos permite comprender la relación entre violencias interseccionales y espiritualidades de mujeres mesoamericanas siguiendo genealogías del Centro de Comunicación Voces Nuestras produjo (2002-2013). Se trata de fundamentar que estas violencias interseccionales pueden ser vistas a partir de las respuestas emancipatorias de lucha y resistencia por parte de estas mujeres. Estas respuestas equivalen a espiritualidades en tanto condensan fuentes de autoridad espiritual, esquemas de certidumbre y estilos particulares en los proyectos de vida de estas mujeres.

Palabras clave: Interseccionalidad; espiritualidades; otro generalizado; otro

\section{Intersectional violence and spiritualities in the life of Mesoamerican} women as theoretical and practical problem

Abstract: The theoretical-practical link can be understood from the distinction established by Herrera Flores (2005b) between the "generalized other" and the "concrete other" to indicate that, deep down, the theoretical-practical leads to the understanding of human subjects embodied in a socio-historical context. From this perspective, said link helps comprehend the relation between intersectional violence and the spirituality of Mesoamerican women following genealogies produced by the Centro de Comunicación Voces Nuestras (Voces Nuestras Communication Center) (2002-2013). The intention is to justify that this intersectional violence can be seen from the emancipation response of these women to fight and resist. These responses correspond to spirituality while condensing sources of spiritual authority, ainty schemes, and particular styles in the life projects of these women.

Key words: Intersectionalit; spiritualities; another widespread; another

Rev. Rupturas 8(1), Costa Rica, Ene-Jun 2018. ISSN 2215-2466. pp 41-70. 
* El presente artículo nace del análisis de historias de vida de mujeres que el Centro de Comunicación Voces Nuestras recogió entre los años 2002 y 2013, en la región mesoamericana. Con base en ellas, pudimos advertir una forma de relación particular, entre las luchas que libran las mujeres en contra de la red de violencias interseccionales que les oprimen y el cúmulo de energías espirituales con que ellas se empalabran para combatir dichas violencias.

\section{Introducción}

La problematización que aquí postulamos plantea la clarificación de categorías de análisis capaces de permitirnos una reflexión teórica entre lo que denominamos espiritualidades de mujeres y algunas violencias interseccionales de que ellas son víctimas, según relatan en sus historias de vida. Una justificación conceptual de los ejes de interrelación entre las dos temáticas, emerge durante el proceso de investigación implicado en un proyecto más general, del cual se desprende este artículo.

Un esfuerzo teórico-metodológico de reflexión sobre espiritualidades e interseccionalidades es abierto a propósito de una discusión conceptual: la discusión de cómo el binomio "teoría/práctica" puede constituirse en un pseudoproblema o en un problema teórico y cuáles efectos tiene el evidenciar esa realidad; se trata de una veta de análisis abierta por Herrera Flores (2005b) cuando elabora la crítica que denomina del "otro generalizado", entonces inaugura para nosotros esta discusión; es decir, este autor, argumenta en oposición a la noción de "sujeto abstracto" (descorporizado, sin necesidades, sin posición-situación social), la noción de "sujeto concreto".

La idea de "encarnación espiritual" permite comprender que el tema de las espiritualidades puede ser visto desde las violencias interseccionales experimentadas por mujeres que, al narrar sus vidas, nos colocan ante un nueva problematización a la cuestión "teórico/práctica", en tanto discusión que no debe separar ambos elementos, sin comprometerse con la síntesis que supone, desde una lectura monista de la vida cotidiana de estas mujeres.

¿Por qué es importante esta problematización? Por una parte, porque el tema "espiritualidad" está imbuido por una tradición teológico-dogmática que lo relega al reino de las abstracciones. Por otra parte, el tema de las violencias interseccionales supone una apelación directa a la compleja gama de encadenamientos (socioculturales; psicosociales, etc.) que nos atraviesan -a todas y a todos- en cualesquiera que sean las circunstancias en que nos toque vivir. Una parte importante del tema de la interseccionalidad entraña una posición crítica respecto de cuáles cuestiones vitales son movilizadoras a propósito de sentirse uno desafiado o indignado: en resumen, se trata de responder a la cuestión sobre si existen espiritualidades encarnadas y cómo pueden verificarse estas en determinadas experiencias de vida, desde su incidencia interseccional.

La fundamentación de esta articulación tiene antecedentes filosóficos y teológicos que no podemos dejar de explicitar en su problematización. Grosso modo, adelantemos tres posiciones formales en el abordaje para dirimirlo o para desaparecerlo como tal: observamos que puede existir la posición que considera que entre teoría (espiritualidad) y práctica (interseccionalidad) existe una radical y absoluta independencia: aquí se decreta una independencia entre los asuntos, que "desaparece" la cuestión; estaríamos ante un pseudo- 
problema, desde semejante dualismo radical. Esta posición podría estar sustentada en la tradición teológica según la cual los asuntos espirituales (cosas de Dios) no tienen ningún vínculo directo con las realidades humanas (cosas de mujeres), como son las que predican que los seres humanos somos seres de factura compleja y que producimos "mundos" que virtualizan horizontes utópicos de producción de trascendencias y que sirven para conocer quiénes somos y movernos ideológicamente -produciendo sentido- dentro de "sistemas-mundo"; dicho así -en resumen- el contenido básico de nuestro concepto de espiritualidad, presupone la necesidad humana de un autoconocimiento capaz de darle elementos para trascender las limitaciones que se presentan en la vida, especialmente de las que -por su violencia y arbitrariedad- generan procesos destructivos de la dignidad de una persona.

Otra posición podría estar configurada desde un dualismo atenuado (respecto del anterior) que consideraría que teoría (espiritualidad) y práctica (interseccionalidades) apelan a realidades paralelas que actúan sincrónicamente por medio de algún mecanismo preestablecido: aquí se apela a algún dispositivo teleológico (de una finalidad pronosticada) que opera, anticipa y programa realizar la conexión entre teoría y práctica. Esta tesis teleológica podría atribuir a "la mano invisible de Dios" la intervención o a otros mecanismos como el que inventó Leibniz (el filósofo alemán) y que denominó de "ideas preestablecidas".

La posición que admite que opera una interacción entre teoría y práctica (espiritualidades e interseccionalidades) y que es legítimo indagarlo y que, con base en ese supuesto, se "escanean" rutas y se sustentan hipótesis sobre las formas cómo actúa esta interacción, porque postula cómo socioculturalmente significante ambas realidades y, sobre todo, necesaria una comprensión de su articulación sin negar que para efectos de análisis la separación coyuntural y formal puede ser aceptable. Nuestro intento de análisis va en esta tercera posición y en línea crítica con las dos posiciones anteriores.

La idea de que un referente fundamental sobre las espiritualidades implica en los sujetos- sus respuestas a las violencias interseccionales, es estructurante de nuestra propuesta. Por ello, vemos dos grandes caminos que se abren en esta dirección; por una parte, podríamos tratar de diseñar rutas por donde encaminarnos. Pero, también, podríamos necesitar identificar rutas por las cuales no-ir: esto es sensato porque el riesgo de perdernos en nuestro cometido, quizá es mayor si no deslindamos el territorio conceptual y sus laberintos.

Es aquí donde hallamos útil el concepto del "otro generalizado", que es presentado por Herrera Flores como una condensación-ideal conducente a una noción de "la mujer" (o del "hombre") en abstracto y, en términos singulares, no marcados por la pluralidad y complejidad intrínseca de la realidad social; el otro generalizado habla del "hombre" o de la "mujer" como si se tratara de sujetos atomizados de derechos y bienes básicos -consustanciales a unas "Iibertades individuales"-, en aislamiento de sus otras condiciones materiales de existencia, como son las vinculadas a sus necesidades más urgentes (alimentación, vivienda, empleo digno, etc.) y a otras necesidades sutiles no 
muy destacadas; por lo general, demandan satisfactores sinérgicos, tales como la necesidad de afecto y la comprensión.

Inicialmente, hemos de señalar que la primacía del "otro generalizado" sobre el "otro concreto", en la modernidad occidental capitalista, responde a la necesidad de todo sistema de dominación de ocultar sus efectos: todo sistema de poder despótico esconde los aspectos injustos que lo originaron y forma parte de esta maniobra la construcción de "mitos fundacionales", cuya finalidades residen en despistarnos respecto de los verdaderos orígenes y finalidades de dominación y explotación de unos seres humanos por otros.

La articulación entre "violencias interseccionales" y espiritualidades en la vida da en el clavo para evidenciar estas simulaciones y distractores; procederemos a presentar estas temáticas clasificándolas en tres subtemas o apartados; en primer lugar, bajo el título de "Las espiritualidades iluminadas por la opaca realidad interseccional" se sitúan el problema y los conceptos principales que sirven de base para el debate. En segundo lugar, bajo el título de "La otra concreta: el discernimiento espiritual desprendido del dolor innecesario la otra generalizada"... se presentan casos y testimonios ofrecidos por las mujeres mesoamericanas que participan en los concursos de Voces Nuestras. En tercer lugar, presentamos el debate, según Herrera Flores, entre las nociones del "otro/a-generalizado/a" y "otro/a concreto/a" y, finalmente, se exponen las principales conclusiones del estudio a modo de reflexiones centradas en la articulación entre espiritualidades e interseccionalidades.

\section{Las espiritualidades iluminadas por la opaca realidad interseccional}

La correlación significante entre nuestro concepto de espiritualidad y las violencias interseccionales, que experimentan las mujeres mesoamericanas, está conforme al hecho de que dichas mujeres narran sus historias de vida; si bien, por una parte, existe una serie de opresiones interseccionales experimentadas que configuran una compleja red potencial y real de violencias a que se ve sometida, concomitante a estas violencias, también se visualiza en las historias de vida una serie de iniciativas emancipatorias de lucha y resistencia por parte de estas mujeres.

Cierto, interseccionalmente, unas violencias convocan a otras; por ejemplo, el ser pobre para una mujer negra o indígena es más violento que el serlo para una mujer que no tendría que lidiar con discriminaciones raciales o colonialistas. Ni se diga si se trata de una niña. Ahí hay que agregar al racismo, al clasismo y al sexismo, el adultocentrismo que la revictimiza. Pero, las energías espirituales de resistencia y lucha también convocan formas creativas de resistencia y lucha en contra de esas violencias sistemáticas e injustas.

Pues bien, las espiritualidades son definidas -según esa correlación- como una relación de comunicación (de producción de sentido global de existencia) 
que estas mujeres establecen consigo en sus búsquedas por trascender los límites que provienen de esas violencias interseccionales de que son víctimas.

A la luz de la narrativa vemos, entonces, que lo interseccional invoca -por una parte- esa cruda realidad de múltiples facetas de violencia sufridas. Y, por otra parte, lo interseccional -de cierto modo paradójico- se visualiza lugar donde se pasa de la experiencia dolorosa a nuevas fuentes de energía (espiritualidad) para la lucha-resistencia de las mujeres; engendradora de una capacidad extraordinaria y creativa de respuesta: las mujeres reaccionan y en sus respuestas emancipatorias verbalizan y actualizan energías espirituales de renovación profunda en sus vidas, liberándose progresivamente de las violencias.

En el material investigado, ${ }^{1}$ las violencias principales son las siguientes: adultocentrismo, diversifobia, sexismo, clasismo, racismo, extraccionismo ambiental, discapacitofobia y dualismos clericales. Todas estas violencias, que son testimoniadas, no son vividas pasivamente por estas mujeres. No es extraño que (estas violencias) resulten fuente de resistencia y de luchas de emancipación que nos permite -siguiendo un análisis de Teología Profanaidentificar cuatro fuertes tendencias de espiritualidad, tales como energía (reactivo) de esas violencias y también como recorridos o itinerarios que estas mujeres construyen en sus búsquedas emancipatorias.

Sus contenidos fundamentales son los siguientes:

1. Nos referimos a nuestra investigación general; a saber, Espiritualidades de mujeres: enfoque

interseccional (Shüssler E.) a la luz de certámenes de historias de vida de mujeres mesoamericanas (Centro de Comunicación: Voces Nuestras). PROY0036-2014. Vicerrectoría de Investigación. UNED.

- Dualismo cuerpo/alma: en este caso, las violencias interseccionales no son confrontadas, sino que siguen vigentes dentro de un marco cultural hegemónico.

- Autotrascendencia del cuidado de sí: en este caso, las violencias interseccionales son confrontadas y experimentan una ruptura (contrahegemónica) con el origen de dichas violencias.

- Inmanencia abierta: esta fuente de espiritualidad cuestiona la violencia interseccional sufrida por las mujeres sin alcanzar una ruptura radical cuestiona las violencias en tanto tales.

- Inmanencia cerrada: esta fuente de espiritualidad, aunque es consciente de las violencias interseccionales en la vida de las mujeres, no cuestiona la fuente de la opresión que reproduce dicha violencia.

Este resumen de los filones de espiritualidades de mujeres mesoamericanas más destacados en el material empírico, se presenta no solo como expresiones paralelas de espiritualidades, sino también incluye itinerarios espirituales o recorridos vividos por muchas de estas mujeres.

La noción de interseccionalidad, por oposición conceptual, podríamos entenderla como ausencia de una espiritualidad del "cuidado de sí"; es decir, que no podemos pretender conocer a alguien (quizá ni al "yo" personal) en términos totales porque el conocimiento interhumano está dado conforme contextos de experiencias y de interacciones siempre parciales y relativas. La lla- 
2. Está embrionariamente en el postulado de Wolf cuando llama a la conciencia del estudio de las condiciones existenciales (de una "habitación propia" o de un ingreso económico digno, de una educación formal académicamente sólida, etc.) como derechos básicos a los que la mayoría de las mujeres se les niega tener derecho, y que al cercenárselos, se ven expuestas a una eterna condición de dependencia y marginalidad. Wolf $\mathrm{V}$. (2008) Una habitación propia. Seix Barral: Barcelona. Accesible en: Ver:

http://biblio3.url.edu.gt/Lib ros/wilde/habitacion.pdf

3. Ver conferencia de Alda Facio inaugurando el año académico 2017; ver: http://www.uned.ac.cr/aconte cer/a-diario/gestion-univers itaria/2807-la-parabola-delorigen-del-patriarcado mada a la consciencia interseccional se lo debemos al movimiento feminista y en especial a pensadoras como Crenshaw, Kimberly Scott y luchadoras como Virginia Wolf. ${ }^{2}$

Esta conciencia de la propia relatividad en el mutuo conocerse y autoconocerse, seguramente tiene un fondo de espiritualidad, puesto que plantea formas de acercamiento interhumano y de intercambio mediado por el "cuidado" y la debida atención; estos dispositivos sutiles seguramente también aportan un protocolo a un concepto de paz interpersonal e intergrupal que cabría reflexionar. En nuestra reflexión, le llamamos "des-rolización"; es decir, ruptura con los mandatos sociales y otros desiderátum culturales asignados desde el patriarcalismo y sus micro-políticas cotidianas de violencia sistemática.

Hemos de señalar que nuestro trabajo apunta hacia una hermenéutica de una espiritualidad promotora de los derechos de las mujeres. En el pensamiento feminista de Young y de Sanders, se evidencian los obstáculos tanto culturales como económicos y políticos, con que se encuentran gran parte de los que de algún modo abstracto se consideran "iguales y libres" para deliberar.

Concluye que, sin una reforma de las condiciones sociales, económicas, políticas y culturales, poco se podrá hacer en beneficio de quienes han sido tradicionalmente marginadas de las ventajas de "los entendimientos compartidos" (Herrera 2005a, 158-159).

Si tenemos en cuenta que tanto las agendas de acción política de los movimientos sociales como las políticas públicas pueden estar marcadas por modelos de análisis interseccionales o por antagónicos modelos de "anticipación racional moderna" (no pareja ni excluyentemente), se comprende mejor por qué un feminismo socialista postula que las diferencias (no las desigualdades) no constituyen un obstáculo a la democracia, sino, al contrario, constituyen un recurso que hay que saber potenciar para no caer en nuevos privilegios y nuevos elitismos. ${ }^{3}$

Teniendo en cuenta el plano teórico-práctico implícito en un concepto de espiritualidad derivado de las condiciones interseccionales de las mujeres, nuestra propuesta de espiritualidad-público-profana (en sentido opuesto a la espiritualidad privatizante, intimista, pura...) dada su contenido, esboza cierta estructura, con tres componentes básicos. No sobra repetir que se trata de espiritualidad desde un enfoque socio-teológico integrador, a la luz de las historias de vida de mujeres mesoamericanas. Tal concepto se caracteriza por presentar tres pautas hermenéuticas de integración teórico/práctica:

- Por una parte, una primera clave interpretativa (teórico/práctica) de nuestro concepto de espiritualidad se ofrece en el orden de la fuente misma de constitución de autoridad espiritual. Esta vertiente de espiritualidad va en línea utópica con un nuevo pacto social (no ciego a las diferencias interseccionales: principalmente étnicas, genéricas, de clase y religiosas, lingüísticas, etc.) al poner en primer plano la necesidad de superar las viejas y nuevas colonizaciones e imperialismos que han proliferado a lo largo de la historia de la modernidad y de las 
percepciones/conceptos de lo religioso; esta clave de integración teórico/práctica otorgará "autoridad espiritual" (por ende, epistémica) a las personas y colectivos que sufren explotaciones particulares (ocultas bajo las máscaras abstractas de los "silencios estructurados" por fuentes de espiritualidades como los devenidos de iglesias tanto como de la filosofía liberal y de sus prédicas principales: igualdad de oportunidades; libertades abstractas de elección). Los contextos interseccionales, sean de etnia, de orientación sexual o de pertenencia a clases sociales subordinadas, etc., así como los ámbitos más potables de emancipación, marcarán la brújula para enfocar diagnósticos y prospectivas de acción en contra de las opresiones más violentas, más cotidianas, etc.

- La segunda clave hermenéutica de espiritualidades está en el ámbito de la legitimidad de sus propios recursos de inteligibilidad: estamos ante las antípodas desarrolladas arriba de un modelo interseccional frente a un modelo de anticipación-racional-moderno. Se postula que el nuevo poder -derivado del primer modelo- debe incluir como pacto social el respeto y la promoción abierta de las diferencias culturales o axiológicas, aún las del modelo de anticipación racional-moderno. Pero, fundamentalmente, propenderá al entendimiento interseccional de la identidad de las mujeres que funcionan, no como un lastre para sí mismo (sí para las imposiciones coloniales, racistas o clasistas) ni como un obstáculo que la razón pública debe trascender (so capa de intimismos-privatizantes), sino como un "recurso público" (en acto y potencia) que da sentido inclusivo al compromiso por la distribución justa de poderes en una democracia, a partir del respeto y promoción de los derechos humanos de todas las mujeres.

- La tercera clave interpretativa (teórico-práctica) de estas espiritualidades profanas-públicas estriba en el empeño puesto en proyectos de vida alineados con un pacto o compromiso nuevo desde el cual puedan garantizarse los resultados de las luchas sociales contra la división social del trabajo dominante y contra todas las viejas y nuevas formas de colonización e imperialismo, que excluyen a la inmensa mayoría de la población y, especialmente, a las mujeres, de los bienes necesarios para llevar adelante una vida digna.

Se trata de un pacto desde el cual no se renuncie a la lucha por los derechos de las mujeres para hacerlos realidad, puesto que una vez que estos hayan sido objeto de reconocimiento formal porque del declarar el derecho de ellas al trabajo, no se sigue que obtengan condiciones efectivamente justas de acceso a un trabajo digno en todas sus dimensiones (remuneración, dignificación como ser humano, creatividad, incorporación válida de sus experiencias subjetivas, etc.).

Para esa incorporación de subjetividad femenina que parta, en todo caso, de la centralidad de la "práctica colectiva de lucha" por la dignidad humana, al margen de las concepciones de libre mercado o juridicismos en que se basan 
-directamente o no- las justificaciones de formulaciones de democracia deliberativa de corte formal (Herrera 2005a, 159-160)

Los espacios sociales desde los cuales se visualiza una espiritualidad profana-pública -en todo caso- alimentan el pacto social que parta de la percepción de las contradicciones y de la privación material bajo las que viven cotidianamente muchas personas y colectivos, históricamente ignorados por el sistema patriarcal, neocolonial, racista y clasista. Y a quienes -hipócritamente, se les "invita" a participar, desde reglas que -de entrada- les privan de todo derecho a expresarse desde lo esencial de sus búsquedas humanas, democrática y legítimamente identitarias. Por ejemplo, vehicula la acción/reflexión de mujeres tradicionalmente excluidas de tantas deliberaciones ideales dadas según una democracia abstracta y representativa.

Sin embargo, quedaría corto este cometido si por acercar a las mujeres a las instancias institucionales donde se materializa formalmente la democracia no se parte de la reflexión acerca de quiénes han sido los sujetos que formaron parte fundacional de dicho pacto. No debe abandonarse la reflexión sobre los límites de los procesos de representación -que han excluido a las mujeres- y, fundamentalmente, no olvidarse, acerca de los orígenes del poder que ha hecho posible que más de la mitad de la población quede sistemáticamente fuera de dichos procesos y de los órganos de decisión política (Herrera, 2005, 162-163).

\section{La otra concreta: el discernimiento espiritual desprendido del dolor innecesario}

Entiéndase este apartado como esfuerzo de contextualización que sirva para ubicar cómo, en ciertos procesos de vida, queda autorizado hablar de la elaboración espiritual de unas mujeres, en la medida que sus esquemas de certidumbre/incertidumbre son conmovidos por ellas mismas: en todo caso, amarrados a experiencias corporales, a sus emociones y a las necesidades comunitarias, de las cuales estas mujeres se saben protagonistas.

Ver las espiritualidades como realidades que se experimentan en el cuerpo, en el emocionar y en las construcciones de colectividades, lleva a una cualificación de los relatos cuyo dispositivo principal funciona al interior del relato; de la interiorización de las historias en sí mismas; se trata de ofrecer una valoración sostenida por la observación y la percepción de las luchas cotidianas como lugar de enunciación

En las historias de vida de mujeres mesoamericanas -según nuestra fuente empírica- el discernimiento espiritual no es casual, ni etéreo. Siempre supone un alto a procesos sistemáticos de violencia: las agresiones en contra de las mujeres de parte muchas veces de sus propias parejas y la decisión de ellas -en su lucha emancipadora- para ir generando su autoridad espiritual; es decir, respuestas reivindicadoras de su dignidad humana como su más "preciada prenda"; al punto de que en su narrativa su lucha es lo que "ella-misma es": 
Cuando se fue definitivamente (mi pareja), yo no sabía que quedaba embarazada de mi quinto hijo. Durante un año, no supimos nada de él, yo no cumplía aún los 23 años y ya estaba en este mundo con cuatro hijos pequeños, uno en el vientre y el mayor apenas con 6 años. No tenía un oficio, nunca había trabajado en nada y no sabía qué hacer. Al principio, me puse histérica, me desahogaba con mis hijos tratándolos con palabras injustas, pero un día reflexioné y me di cuenta que ellos no tenían la culpa de lo que estaba pasando, más bien, eran las principales víctimas y comencé a tratarlos con cariño (2007, 40: Ada Luz Cuadra. La Maravillosa Experiencia de mi vida. Estelí).

En el núcleo del relato acontece un "alumbramiento" de discernimiento espiritual; un chispazo que sacude el cuerpo en medio de los límites críticos que se vivieron; se trata en síntesis de sus propias percepciones respecto de aquellas "experiencias decisivas", en su búsqueda de alternativas para aqueIla "vida". Ada Luz tomó decisiones que fueron hitos o puntos de inflexión en su biografía.

A posteriori, las reflexiones de quien vivió la experiencia dolorosa permiten dilucidar las rutas por donde se ha transitado: atribuir un valor a los hechos, como quien se atreve a estimar la propia vida, haciendo balances, re-visándola. Según se construye y reconstruye Ada Luz, ilumina el contexto de sus alternativas; retoma su vida dudando de si será algo por lograr, pero se le nota la certeza de que asumió, en la cuota que tocaba, la decisión justa.

Las imágenes y las metáforas a que acuden las narradoras son múltiples; sin embargo, en las palabras de Zaira hallamos una clave metafórica ajustada a su percepción general de vida, aplicable a muchas de los relatos, aunque estamos claros ella habla de ella y para ella:

Nuestra vida es como un rompecabezas al que vamos agregando piezas, aun cuando muchas de ellas, debamos de apartarlas para seguir adelante. En mi vida, existen muchas piezas grandiosas como los tíos y tías quienes amorosamente abrieron sus hogares, primos y primas a quienes amo como hermanos, vecinos solidarios, pero, primordialmente mi madre quien inculcó valores 
morales muy fuertes y quien siempre de manera honesta sigue luchando por todos nosotros ¡Ella es un vital fundamento de mi existencia! $(2004,142)$ (Zaira Marín Segura. Los fundamentos de mi existencia. Ciudad Quesada. Sn Carlos).

La escritura se convierte en una herramienta de lucha, en otro modo de recuperar la voz, de agregar valor-y-lucidez a lo que se vive: la consciencia que refleja la vida como fuente del aprendizaje-del-vivir; del saber-sobre-sí-misma:

He vivido luchando por superarme responsablemente, a pesar de los obstáculos que día a día nos encontramos en este camino, donde todo no es felicidad, en donde las cosas se logran a través de nuestro propio esfuerzo. Sólo de esta manera lograremos cumplir nuestras metas, solo de esta manera lograremos ver realizados nuestros sueños. Hoy, mi mayor anhelo es poder dar a conocer algunos de mis poemas, con los que sé que ayudaría a mucha gente, al igual que yo aprendí; pero, sobre todo, quiero demostrar, con mi ejemplo, lo que se puede lograr si se sabe luchar, si aprendemos a decir "yo también puedo y valgo mucho como mujer", independientemente de la condición física, moral, intelectual y económica. Simplemente esa soy yo: Mujer. $(2007,83)$ Viela Cristina Saborío Monge.

Lo primordial de estos esquemas de certidumbre/incertidumbre apreciados como rompecabezas es que aportan discernimiento de sentido global a la vida, del proyecto de vida emprendido, habilitando a quien escribe una lectura de conjunto de su propia vida y no rara vez por una vía muy dolorosa, en la que la mujer asume desafíos que definitivamente, la llevan a tareas imposibles:

Después de 3 meses nos pasamos a vivir solos, pues yo ya podía hacer las cosas de la casa, así le quedaba más cerca el trabajo a Ronal y nos veíamos todos los días. 
Entonces, empezaron los problemas. Él comenzó a tomar, llegaba tarde, yo me sentía sola y en una ocasión no aguanté más, tomé mis cosas y me fui para Ciudad Quesada. Le dije que, si él no cambiaba, yo no regresaría. Pasó un tiempo sin tomar, pero después otra vez lo hizo, yo lloraba de ver que mi vida era como el pasado de mami, pero aguanté y recé mucho porque él dejara eso, si él no tomara fuera perfecto, pensaba yo, él nunca me había alzado la voz ni me había pegado, en lugar de eso me pedía perdón cada vez que tomaba. Yo comprendía que era una enfermedad, pero si él ponía de su parte podría superarla, así que lo aconsejaba y lo trataba con amor. Logré que dejara un poco de tomar, sé que Dios me puso en su camino para ayudarlo y para que yo me ayudara. $(2007,35)$ Aida Lina Castillo Rodríguez.

Una comprensión de "lo espiritual" en la vida de las mujeres mesoamericanas, a partir de aspectos como el narrado por Aida Lina, revela hasta qué punto lo espiritual figura en contra de su propia seguridad personal como puro sacrificialismo: sufrir, una y otra vez, las secuelas de la violencia machista, resultan medios que no dejan ocasión para las búsquedas de pautas de espiritualidades más autónomas y asertivas respecto del "cuidado de sí".

En cierto sentido estamos interpretando que existe una relación causal entre la violencia interseccional y cierta espiritualidad hegemónica que reproduce la violencia patriarcal; hasta que la experiencia de vida es llevada a un plano de inteligibilidad básica, estas mujeres experimentan una cierta dosis de autocuidado mediando esos esquemas de incertidumbre. Llamar a cuentas a la violencia vivida, se torna esencial, al menos, por tres razones:

Primero, la relación entre opresión interseccional (como experiencia decisiva) y espiritualidad como "cuidado de sí" conduce a la mujer a oponerse a ella, conduce a fundar cierta autoridad espiritual en cada mujer violentada entiende que debe ofrecer otra respuesta a estas violencias sistemáticas. Aida Lina decide no reproducir en su vida la violencia machista que vio padecer a su madre.

Segundo, en los casos que nos ocupan es la mediación del relato de vida (testimonio) lo que facilita que las mujeres hagan inteligible para sí y para otras sus experiencias decisivas. En términos de Aida Lina, ella compara su genealogía con la de su madre, gracias a su lectura global. Este esquema de inteligibilidad es más meritorio cuanto que los apoya en una lectura crítica de 
lo que sucedió con su madre en el contexto del patriarcado hegemónico que esclaviza para que las mujeres esclavizadas reproduzcan dicho sistema.

Tercero, hallamos en el despliegue total de cada historia y del conjunto de historias de vida de las mujeres, la visualización de proyectos de vida como un esfuerzo de respuesta/posición/humana-radical (espiritual) ante la realidad contundente, violenta, que se les impone: la serie de opresiones interseccionales que las quieren encadenar, eternamente, empieza a ser debilitada en alguno de sus eslabones.

En esta lectura global de la existencia, las mujeres se permiten discernir lo recorrido, y lo hacen desde un lugar-momento idóneo para llamar a cuentas, con lucidez espiritual. Renace una relación comunicativa fundamental con lo que le ha re/construido-como-mujer: una relación comunicativa consigo-misma, en primer lugar:

A los 16 años tuve mi primer hijo y todo marchaba normal. Me fui llenando de hijos porque a él no le gustaba que planificara y yo era muy sumisa, obedecía todo lo que me decía. No me dejaba estudiar y tampoco aprender un oficio, pensaba que la mujer que trabajaba fuera de la casa traicionaba al marido. Cuando tenía cuatro hijos, la relación se complicó, él se enredó con otra mujer. Días antes de irse definitivamente, me dijo que si me dejaba las niñas iban a ser prostitutas, porque eso era lo que yo les iba a enseñar y que el niño seguramente sería un vago. Me dolió mucho que el padre de mis hijos les pronosticara ese futuro y le dije que un día se tragaría las palabras que había dicho. $(2007,39)$. Ada Luz Cuadra.

Consideramos que las palabras de Ada Luz en el fragmento seleccionado se asienta una respuesta (ante la violencia interseccional dominante) que releva su posición de género (de identidad femenina) al punto que cierra con la frase: "... un día se tragaría las palabras que había dicho"; la lectura de la historia permite confirmar un proyecto de vida en ella que lo confirma. Sin embargo, no está demás señalar lo dificultoso que resulta identificar cuál puede ser la intersección dominante en ciertos casos, como el siguiente:

Cuando murió mi madre, mi papá nos dejó terminar ese año, pero no nos daba plata, entonces nosotras teníamos que coger café los sábados o en las horas que tuviéra- 
mos libres en el colegio, por lo menos para pagar el almuerzo, que en ese tiempo costaba $\$ 20$ por semana y no podíamos descuidar los quehaceres de la casa. Teníamos que levantarnos en la madrugada y dejar todo hecho, una lavaba, la otra limpiaba y la otra cocinaba pero, a pesar de esto, queríamos estudiar. Para el siguiente año, mi papá nos dijo que no íbamos a ir al colegio porque alguna tenía que quedarse en la casa y no era justo que unas estudiaran y otras no. Desde entonces quedó un sueño frustrado, que era llegar a tener un bachillerato y realizarme como profesional. Estando joven tuve varias opciones de trabajo, porque yo era una persona muy activa, pero siempre me pedían el bachillerato o, cuando mínimo, el noveno y yo solo había estudiado hasta octavo (2007, 84-85) Miriam Vargas Estrada.

No es transparente aquí cuál es la violencia interseccional a la que responde Miriam: ¿Hasta qué punto la decisión adultocéntrica de este padre que impide estudiar a las hijas es más importante para la narradora que la justificación económica que les obligaba a no tener suficientes recursos para poder estudiar? ¿Por qué detenerse en consideraciones etarias y no en otras y por qué no asumir como relevante el hecho de que la narradora habla de que todas las hijas mujeres son las que experimentan la limitación de no poder estudiar en el contexto de la vida familiar? Poco a poco, al adentrarse en la historia completa, se evidencia que la posición de Miriam estriba en comprender que la subordinación de la mujer dentro del régimen del patriarcado es la clave de comprensión de la cadena de opresiones interseccionales que padece: su lucha estará entonces marcada por la conciencia de ser-mujer, según puede leerse después:

No lo podía creer, fueron 26 largos años de esperar este sueño (obtuve el bachillerato); no tuve tiempo de emocionarme, hasta el otro día como que ya fui entrando en conciencia de lo que yo había logrado con mucho esfuerzo, con la ayuda y el apoyo incondicional de mi esposo. Hoy dedico este triunfo a las dos grandes mujeres que se me fueron y no pudieron estar aquí conmigo para celebrar: a 
mi madre (soy la única hija que logró este título) y a mi maravillosa y valiente amiga Margarita Hidalgo $(2007,88)$ Miriam Vargas Estrada. Hoy y no mañana. Venecia. San Carlos

Si catalogamos a las identidades como inherentes a las interacciones, conscientes de la complejidad que entraña ir "definiendo y redefiniendo" continuamente la realidad de quiénes somos, el punto fundamental estriba en reconocer que esa dinámica de definición/indefinición siempre se realiza a partir de cómo nos estamos sientiendo/convirtiendo in situ. No existe identidad que no esté enraizada, situada, contextualmente y esto puede traducirse bajo una concepción dinámica que se debate entre un sustrato de sí que permanece (porque nadie puede quedarse sin una autocomprensión suficiente para funcionar social y psíquicamente) frente a los desafíos cotidianos que llevan u obligan a cambiar en esos mismos planos.

Así nos lo refleja una mujer nicaragüense:

Soy una Mujer de 35 años, desciendo de una familia humilde, hija de una maestra de primaria. Desde muy pequeña sufrí por mi hiperactividad, tenía mucha energía y me decían "loca", "inquieta", "alborotada". Me repetían a cada momento que "las niñas eran señoritas que debían ser bien portadas". Nada de locuras, me decían, no corrás, cerrá las piernas, las niñas no gritan, en fin; nadie aceptó nunca que una niña puede ser una niña. Decían, también, que debía aprender todos los oficios que una mujer debe saber, que necesitaba rienda, "porque si no, el hombre me iba a dar palo y, a lo mucho, me iba a dejar". Aunque no entendía la fuerza de esas palabras, porque las había escuchado desde siempre, sonaban naturales para mí, pero nunca acepté que un hombre me golpeara. Soñaba con héroes y cuentos de hadas, me regañaban por todas las cosas que inventaba, pues fui criada bajo fundamentos religiosos por mi abuelita, una fiel devota de la iglesia (2007, 108-109). La Boletina. 
Una comprensión socio-cultural justa de las luchas de las mujeres en contra de las violencias interseccionales, lleva a la comprensión de que estas luchas no se dan en contra de su propia decisión: no basta con entender la propia situación como producto de los procesos de una estructura del patriarcado sin la voluntad de combatir la imposición de un solo tipo de "ser-mujer" bajo las micro-políticas que se le recetan en consecuencia; roles predecibles con patrones pre-determinados, sin oponerse ni chistar, modos de ser únicos y formas pasivas de estar en el mundo.

Los procesos identitarios, sabemos lo que nos dice arriba la narradora nicaragüense, no se producen de un modo transparente para la persona ni siempre figuran linealmente sostenidas las formas de violencia de modo que ella perciba el alcance del daño que potencia. Por eso, son procesos que tardan, conscientemente, en ser identificados. En los casos que citaremos, veremos la complejidad en estos procesos de búsqueda, contradictorios vividos en medio de opacidades.

\section{Debate según Herrera Flores: "otrola-generalizadola" y "otro/a concretola"}

Uno de los postulados fundamentales para nuestro estudio comparado de espiritualidades estriba en no idealizar dichas espiritualidades, así como tampoco naturalizar las violencias interseccionales vividas por las mujeres, ya que ni las víctimas de esas violencias las experimentan más que como lo que son (violencias que causan daños visibles y simbólicos) ni tampoco nuestro concepto de espiritualidades se alimenta de una percepción sadomasoquista de los cuerpos, emocionalidades y comunitariedad de las mujeres.

Las violencias interseccionales son el envés de las espiritualidades según nuestra hipótesis en las experiencias de vida que nos sirven de referencia, pero eso no significa que a más violencia, más espiritualidad: significa eso síque aún en condiciones extremas de exposición a la violencia, estas mujeres fueron capaces de salir del círculo de violencia que las ahogaba y esa emancipación les dota de una autoridad espiritual, sin ninguna duda.

Situaciones como esta nos parecen de suma riqueza para reflexionar sobre la articulación entre teoría y práctica, a propósito de la unidad profunda que une a estas dos categorías. La cuestión de fondo a la que quisiéramos abocarnos bien puede ser resumida en la pregunta: ¿qué importancia puede tener abordar teóricamente situaciones de tan extrema y compleja violencia cotidiana? ¿Será un ejercicio ocioso, incluso doblemente castigador de la realidad de estas mujeres, el reproducir sus situaciones como quien exhibe ropa en un tendedero?

Reflexionando las experiencias biográficas descritas en los certámenes de Voces Nuestras, a la luz de los conceptos de Herrera Flores sobre "el otro generalizado", uno se halla con la crítica del autor a las visiones y tendencias empiristas muy al calor del positivismo cuando suelen despreciar la teoría como algo adueñado por una casta intelectual (abstraída), que rechaza la 
práctica como algo estrecho y que, desde cierto concepto teórico elitista, se niega a comprender los alcances efectivos de la trama vital.

Esto equivaldría, para ir al caso, a reducir la problemática de las mujeres que participan en los certámenes dichos, dentro de una problematización pobremente amarrada a una noción del orden práctico en términos empiristas cuya única justificación quedaría tolerada solamente dentro de los parámetros de una búsqueda de resolución pragmática; por ejemplo, en esta línea demandaría acciones, legales entre otras, para la emancipación de situaciones ostensiblemente injustas.

Llevado esto al extremo, podría alegarse que las instituciones, incluso universitarias, no deben dejar entrar las voces y las utopías que podrían transformar a fondo esas situaciones, a veces, bajo el lema de que algo es "demasiado abstracto" (irrealizable) se le opone artificialmente a "lo práctico". Esto último como entidad anclada a necesidades agotadas en lo perentorio, como si estas solo pudiesen ser vistas de modo muy reductivamente inmediatista.

En resumen, negar la estrecha relación entre teoría y práctica legitima textos y discursos en función de un aparato institucional hegemónico. Asimismo, esa negación relega las narraciones o relatos testimoniales bajo los cuales la gente especialmente la excluida de los procesos de creación de opinión pública hegemónica se expresa cotidianamente.

Una aproximación más ecuánime interrogaría ¿desde cuáles prácticas teóricas se accede a un enfoque interseccional o de opresiones superpuestas vinculante con fuentes de espiritualidades? Conscientes de que, dadas las tradiciones religiosas al uso, el tema "espiritualidad" ligado a las violencias cotidianas puede sonar demasiado "terrenal": esto denominado espiritualidades suele ser visto como una especie de entelequia celestial, próxima a quienes ya en la tumba esperan por la beatificación romana. Pero, ¿qué le hace el tema de las violencias interseccionales vividas por mujeres al tema de las espiritualidades? En nuestros términos, las encarna.

El hecho de que sostengamos que existe una correlación entre violencias interseccionales y espiritualidades está sustentado en que identificamos un concepto de espiritualidad intrínseco a la lucha/resistencia de mujeres mesoamericanas que sufren violencias: estas mujeres responden a ellas con la radicalidad emancipatoria que renace de la conciencia de su propia dignidad humana mancillada. Esto nos lleva a un concepto de espiritualidad como capacidad de producción-comunicación de auto/trascendencia respecto de los límites y daños que provocan esas violencias.

En otras palabras, consideramos que la "relación comunicativa" de estas mujeres consigo mismas cambia radicalmente inaugurándose un itinerario espiritual de signo emancipatorio.

Observamos que ciertas percepciones y conceptos antropológicos de raíz dualista persisten en la cultura (especialmente en la religiosa) trasladando en los discursos modernos el mencionado humanismo-dualista-abstracto. Siguiendo a Herrera Flores (2005b), el tema es resumido bajo el lema de la 
presencia de "un/a otra/o generalizado/a", que es básicamente un "ser abstracto" (reducido a un "tu generalista", que no habla de nadie porque pretende hablar de todos) opuesto frente a otro "tu-concreto" como sujeto que habita el mundo-cotidiano desde posiciones de desigualdad: a diferencia del primero, el segundo tiene que luchar cotidianamente para acceder a los bienes necesarios para vivir, que, dada su situación de opresión y explotación, no tiene otro remedio que actuar para ir eliminando los obstáculos que a su dignidad le imponen los procesos de división social, sexual, étnica y territorial del trabajo, y que en esas luchas sociales, económicas y culturales va autoimponiéndose compromisos y deberes que la unen colectivamente con otras y otros, en espacios sociales y esferas de responsabilidad y reconocimiento mutuos (Herrera 2005b, 125-126).

En la historia de la discusión que nos conduzca hacia una comprensión interseccional del problema, hemos de seguirle la pista al debate entre quienes abanderan una teoría u otra ("otro generalizado" y "otro concreto") para una comprensión cabal del problema que tenemos entre manos: en esa búsqueda encontramos el punto de partida en un trabajo pionero: el de Gilligan Carol (1985). Para Herrera (2005b, 26-27), por un lado, estaban quienes fundamentaban la modernidad en un pretendido contrato social firmado por seres iguales "a priori": que se autoconciben como seres independientes, autónomos, recíprocamente desinteresados, materialmente irresponsables ante lo que les ocurre a los demás y, por consiguiente, según la tesis de psicólogos como Piaget y Kohlberg, suficientemente maduros para formular principios universales "a priori" tanto en lo que respecta a la acción social como al reconocimiento de los otros (autores que partían, pues, del "otro generalizado").

Por otro lado ("el de la otra-concreta"), estaban autoras y autores que consideraban la madurez intelectual, no como entrada en el tiempo universal, sino como la capacidad de situarse en el espacio de lo concreto, en el espacio de la responsabilidad y del compromiso con las vidas cotidianas de todos los seres humanos que, de un modo u otro, están implicados en las luchas por la satisfacción de los bienes necesarios para una vida digna.

Gilligan C. (1985) situaba su perspectiva en esta línea crítica y en el debate con quienes sostenían tesis contrarias, afirma una ética femenina/feminista separada de los postulados de Piaget y Kohlberg, pues tenía menos que ver con principios universales a priori de aquellos que con el "cuidado" de aquellas personas que tenemos a nuestro lado y con el reconocimiento de intereses colectivos concretos de personas y grupos afectados por su posición en procesos sociales concretos y reales.

La autonomía, para la autora norteamericana, no coincide con un espacio propio que reniega de la intervención ajena (mi libertad termina donde comienza la tuya) sino con la adquisición de un poder colectivo y social suficiente para ejercer una solidaridad activa con los que sufren (mi libertad empieza ahí donde comienza la tuya).

De este modo, frente al canon moral de corte masculino dominante basado en el "otro generalizado" impregnado de una hipotética, pero políticamente 
4. Ver debate en Youtube, entre Adela Cortina y Enrique Dussel, sobre ética del discurso y ética de la liberación: accesible, en: https://www.youtube.com/w atch?v=zRGj8dlJYBE eficiente, matemática moral homogénea jerarquizada en función de principios a priori, Gilligan opone y reivindicaba una narrativa y una retórica plural justificable (Herrera, 2005a, 26) no desde principios a priori sino desde las luchas cotidianas de mujeres contra los procesos de división social y personal del trabajo a que son sometidas desde las relaciones capitalistas de producción: pero, incluso, la autora remonta más atrás del sistema capitalista los mandatos impuestos ancestralmente a las mujeres y, por extensión, a todos los colectivos oprimidos "otros concretos" y denuncia por su sesgo ideológico toda matemática cosificadora de estas relaciones de desigualdad e injusticia.

Herrera Flores contribuye a discernir el fondo de esta polémica (2005b, 127) bajo la discusión del viejo problema entre teoría y práctica: deviene de ahí su crítica a ciertas teorías tendentes a generalizar y formular leyes y mitos con pretensión de universalidad desde una noción de prácticas sociales cercanas a las luchas sociales por la dignidad. Esto le permite al autor comprender que lo que está en disputa no consiste en dejar al abandono las reflexiones "generales" para sostenerse y permanecer en el momento "puramente concreto" de la vida cotidiana; esto implicaría quedar presos de las redes de las éticas dominantes que, como la del mercado capitalista, nos inducen a no pensar más en fundamentos y dedicarnos únicamente a poner en práctica lo ya justificado y legitimado por ellas.

La cuestión es mucho más compleja, pues su resolución de la polémica "teoría/práctica" no consiste únicamente en apostar por uno de los polos de la cuestión: la teoría o la práctica, sino de la reflexión acerca de su mutua interacción entrambas (Herrera 2005b, 127-128).

\section{Crítica al pensamiento esencializador presente en algunos "modelos ideales" (Herrera Flores).}

Durante todo el último tercio del siglo XX, la teoría crítica de la sociedad, y en especial una determinada corriente del feminismo, deudora en parte de Habermas y Rawl, se empeñó en encontrar límites normativos "racionales" a las propuestas neoliberales o sistémicas del "otro generalizado" que funciona poniendo en práctica la "elección racional" (rational choice).Tanto los modelos teóricos de Jürgen Habermas, como los de John Rawls, han pretendido, cada uno desde su respectivo campo de acción, establecer límites normativos $^{4}$ a las aplicaciones más o menos irracionales del mercado capitalista (Herrera 2005b, 127-128).

Habermas inicia planteando la exigencia normativa de establecer cauces procedimentales "ideales" que no estén contaminados por las posiciones más recalcitrantes del neoliberalismo. Y Rawls afirma, desde un presupuesto puramente economicista, que no se pueden deducir principios racionales de justicia, porque como buen neokantiano encuentra en el "mero pensar racional" las categorías que nos salvan de las atrocidades de los modelos neoliberales.

Herrera Flores (2005b,128-129) plantea dos cuestionamientos de fondo a estos autores: ¿es factible enfrentarse a abstracciones desde abstracciones e 
idealizaciones a priori? ¿Es el mercado una categoría sin moral y sin ética? Es decir, si nos enfrentamos moral e idealmente a las teorías que justifican el mercado libre (autorregulado) ¿estaremos dejando los hechos en los que se basa la ética del mercado al margen de todo cuestionamiento? Mientras nosotros nos preocupamos por los criterios morales y procedimentales de "corrección", la maquinaria irracional del sistema financiero continúa su proceso de destrucción.

Para el crítico, el problema de situarse en la tensión establecida entre el "otro generalizado" y el "otro concreto" afirmando la primacía del segundo a la hora de reflexionar sobre problemas reales (como los derivados de la mercantilización de la vida), supone enfrentarse a las teorías que de un modo u otro esencializan al sujeto y el conocimiento: en el fondo, planteando como universales ("otros generalizados"), lo que es un producto de una concepción cultural particular (mercantilización de la vida).

Por ello, gran parte de la teoría feminista más consciente del enemigo que hay que afrontar, se ha dedicado a identificar y visibilizar los presupuestos teóricos y políticos que subyacían a las diferentes versiones "generalizadoras" sobre la acción social, sea la situación ideal de comunicación de Habermas o los principios "racionales" de Justicia de John Rawls.

Las colisiones entre estas teorías generalizadoras y las propuestas teóricas antipatriarcales han sido constantes, dado que tales generalizaciones teóricas, a pesar de su virtualidad en otros campos, no dejan de sustentarse en una visión esencialista del sujeto y en un tipo de conocimiento validable únicamente por su capacidad de representación epistémica: en resumen, la teoría se valida por la misma coherencia y circularidad de la teoría (Möller, 1996) y mucho menos por sus anclajes efectivos en los procesos socio-políticos y sociales concretos.

Situada en su naturaleza ideal, toda anticipación racional, según Herrera Flores, principalmente constituye un esfuerzo intelectual por enfrentarse al problema colectivo que supone la dialéctica entre las necesidades y sus posibilidades de satisfacción. ¿Qué hacer frente a una sociedad, a un contexto social, manipulado y ensombrecido por los valores que imponen la tecnología y la racionalidad instrumental? ¿Es capaz tal racionalidad de captar y ayudar así a solventar problemáticas que demandan satisfacción de necesidades ajenas a lo que dichos esquemas de certidumbre racional se plantea? ¿Puede el esquema de certidumbre de anticipación-racional-moderno avanzar hacia una autocrítica capaz de poner en duda sus propias certezas apriorísticas?

En el plano de lo institucional, ¿cómo reaccionar frente a los que se oponen a algún tipo, aunque sea mínimo, de planificación social e institucional que afecte a las condiciones vitales mínimas de los que han tenido "mala suerte" en la distribución originaria de los bienes públicos?

Habermas propondría la anticipación de una situación ideal de comunicación que pusiera en evidencia tales intromisiones autoritarias en el mundo de la vida (personal e institucional) y Rawls anticiparía un universo político ideal 
basado en principios a los que todos llegaríamos con solo pensar en cómo relacionarnos sin tomar en cuenta nuestras situaciones presentes y futuras de privilegio (Herrera 2005b, 129-130).

Sin embargo, para Herrera Flores, el remedio puede ser peor que la enfermedad. Sobre todo, si se cae en alguno de estos dos supuestos:

- La anticipación racional "a priori" solo se valida por sí misma, es decir, por su capacidad de autorreproducirse al margen de las situaciones concretas en las que supuestamente pretende interferir. Con ello, quedarían de nuevo invisibles las desfiguraciones y las disfunciones reales y materiales que estaban en el origen del surgimiento de la teoría, desapareciendo todo esfuerzo por aclarar y controlar el contexto de descubrimiento en favor de la primacía del contexto formal teórico y abstracto de justificación.

- La construcción o la anticipación racional agota en sí misma la propia finalidad de la reflexión teórica. Al vincular las cuestiones políticas concretas, es decir, la expresión de las luchas y los anhelos de los que sufren una u otra cara de la opresión, con una teoría previa de lo racional, se corre el peligro de considerar como único objeto del razonamiento crítico el perfeccionamiento epistémico de la propia anticipación racional. Caeríamos en la "miseria de la crítica", o sea, en el reduccionismo epistémico que difumina los "fines" reales de la reflexión, que no deben ser otros que la resolución de las diferentes facetas de la opresión (Herrera 2005b, 129-130).

Suponemos aquí que la problemática que aporta el contexto de descubrimiento de toda teoría, es decir, la opresión, la subordinación, la explotación de unos colectivos por otros, no debe desaparecer de los intereses del que reflexiona. ¿Qué ocurriría si el contexto de justificación/legitimación de dicha reflexión, o lo que es lo mismo, los presupuestos abstractos de la teoría que se formula se dirigen únicamente a conseguir y resaltar la propia validez formal de la anticipación racional que se ha hecho mediante la teoría?

Sea en la situación de comunicación ideal o en la formulación racional de principios de justicia, tales anticipaciones o formulaciones "a priori" amenazan con "dejar intacto" el mundo de las diferenciaciones y las desigualdades sociales sobre el que ineludiblemente se levantan, convirtiendo los procesos de división jerárquica y desigual del hacer humano, en algo invisible para la acción y, por ello, para el pensamiento.

Ilustrativamente, no sirve de mucho animarse por las expectativas democratizadoras que podrían introducir en las relaciones sociales algunas tecnologías que revolucionan el campo energético (energías distribuidas) o de la producción (internet de las cosas) si se deja en la sombra, el hecho de que tanto las nuevas tecnologías energéticas como las de producción pueden seguir estando monopolizadas por unos cuantos, dentro del esquema mercantilizador que al fin de cuentas se encargará de reducir toda la promesa democrática a 
partir de tales tecnologías a meras mercancías para el lucro y la imposición política.

En vez de considerar las ideas como situadas en los contextos sociales donde interactúan los sujetos, el "discurso de competencia" y racional "a priori" coloca al sujeto y sus relaciones en las ideas. Con esto, la abstracción deja de ser un esfuerzo por trascender e ir más allá de lo que no se considera relevante para las finalidades prácticas del discurso y se convierte en un esfuerzo ideológico que intenta salvar, perfeccionándolo formalmente, un modelo teórico previo que, al final, tenderá a presentarse como la formulación de una esencia de carácter universal. Es decir, intentará salirse de los circuitos de la reacción cultural y, con ello, de toda posibilidad de transformación o alternativa (Herrera 2005b,130-131).

¿Qué es lo que en el fondo se debate entre dos modelos-teóricos? (Razón o interseccionalidad)

Aun cuando la anticipación de una comunidad ideal racional (Iglesia u otra institución igual o secular) pueda aportarnos criterios normativos y esquema regulatorios para un enjuiciamiento sensato de la realidad, la posibilidad de absolutizar sacándolo de los circuitos de su verdadera reacción cultural el argumento abstracto; es decir, de autoimponer el patrón normativo propuesto racionalmente (posición oficial y monocultural de lo que se defina como espiritualidad), entraña riesgos tales como

- La neutralización de la historia: la historia será invocada teleológicamente a modo de un guion cuyo final conocemos.

- La abolición de las diferencias: la estandarización impondrá su ley ya que las diferencias se tornarán insignificantes respecto de los modelos ideales que se ofrecen como herramientas pero que se convierten en "camisas de fuerza".

- El ocultamiento de las contradicciones reales: las principales contradicciones de la realidad estarán absorbidas por el afán generalizador idealizado.

- El abandono de toda tentativa de interrogación sobre modos alternativos de visión y tratamiento del aspecto concreto referencial: sea una situación comunicativa, sea una opresión en razón del sexo, la clase o etnia, edad, diversidad, etc.

Así, los intentos por anteponer una única y determinada anticipación racional (dígase esquemas de certidumbre/incertidumbre) a las múltiples realidades concretas (espiritualidades $u$ otras) en las que nos debatimos cotidianamente (sea esta la competencia perfecta, la planificación centralizada, la acción comunicativa o la racionalidad a priori de individuos representativos) se tenderá a establecer una separación tajante entre la acción de los sujetos que forman parte de tales "anticipaciones" (sus versiones hegemónicas) y las situaciones 
sociales, económicas y culturales que están a la base (contexto y fuente de las prácticas sociales concretas).

Así, tales anticipaciones pueden caer en una contradicción de importantes implicaciones políticas y filosóficas: al pensar el mercado, la planificación institucional o la praxis jurídica y política en términos anticipadores cargados de una fuerte tendencia a oponer algún tipo de pureza ideal a las impurezas de la realidad, siempre se las construye bajo términos de ausencia: en el sentido económico, por ejemplo, una competencia perfecta implica la ausencia de la función real de la competencia; una legitimación perfecta supone la ausencia de la función social de la legitimación; un acercamiento perfecto de las leyes implica la ausencia del sistema legal real.

Al anteponer absolutamente una construcción racional a las situaciones concretas de los individuos y grupos que actúan en el mercado, en la política o en la reflexión sobre principios, los problemas reales parecen desaparecer.

Por ello, al abstraerse de las condiciones reales que potencian una u otra facetas de la opresión, la anticipación ideal de comunidades de comunicación o de formulación de principios racionales, a priori, se llevan a cabo sin contar con las comunidades reales de comunicación, y la anticipación de procedimientos universales de obtención de principios se hacen sin contar con los procedimientos reales de la formación y elaboración de la conciencia pública.

Esa "ausencia de lo real" provoca que las anticipaciones racionales coincidan con el discurso instituido como discurso competente. Esto es, con un discurso en el cual los interlocutores fueron previamente reconocidos como los que tenían el derecho de ser oídos y de-poder-hablar, en el cual los lugares y las circunstancias ya fueron predeterminadas a la hora de permitir hablar y oír y, en fin, en el cual el contenido y la forma ya fueron autorizados según los cánones de la esfera competente. Si, como sucede corrientemente en la acción social, los grupos y los individuos así situados pretenden encontrar el sentido de su acción en tales aproximaciones anticipadoras separadas de los contextos reales donde dicha acción se lleva a cabo y, como por lo general ocurre, en dichos contextos la situación es completamente otra a lo que se anticipa racionalmente o no coinciden con lo que está social y políticamente instituido, la crisis y la neurosis social -bases de la pasividad ciudadana- están aseguradas.

\section{Efectos derivados de la teoría en la lectura-discursividad de la realidad}

¿Significa, según la lógica de nuestro discurso, que la reflexión crítica debe renunciar por principio a criterios de anticipación racional moderna?

De todo esto se deduce que toda anticipación servirá para la reflexión crítica solo cuando asuma que su naturaleza depende de su propia imperfección, de que "existe solamente porque existe en términos imperfectos". Es el caso de la distinción público-privado: si una teoría política utiliza como criterio normativo de corrección la primacía de lo público-institucional, concibiendo lo privado como el reino de la manipulación y la subordinación, lo público aparecerá 
entonces como la "anticipación racional", como el ámbito de lo perfecto, mientras que lo privado es visto como el "espacio residual" que, en el mejor de los casos, controle los desmanes de la abstracción.

Lo anterior implica una doble consecuencia y nefastas ambas:

- Ignorar y no tomar en cuenta luchas, prácticas o acciones no institucionales llevadas a cabo por quienes tradicionalmente se han visto privadas de aparición pública: léase el caso del trabajo no remunerado e invisibilizado de las mujeres, por citar un caso ejemplar de invisibilización de lo visible.

- Pensar que la solución consiste en abandonar el ámbito de lo privado manipulado y subordinado para integrarse plenamente en el de lo público-institucional, como si este fuera el reino de la libertad: véase el caso de las reivindicaciones indígenas sobre su derecho al territorio, descafeinadas al integrarse en el debate jurídico-político acerca de los derechos de propiedad. ${ }^{5}$

5. En términos de Herrera Flores (2005), estas luchas

Aunque estas consecuencias constituyen los mecanismos ideológicos más frecuentes en cualquier tipo de justificación colonial e imperialista, lo que nos interesa resaltar aquí es la necesidad de instituir un pensamiento y una práctica que apueste por la interrelación de espacios en este caso, públicos y privados y no por la superposición de uno sobre el otro (Herrera 2005b: 132133).

Aparte de postular que las historias de vida constituyen un referente empírico de primer orden para avanzar este cometido epistemológico, que evite incurrir en las invisibilizaciones denunciadas, vale atacar directamente las presunciones del modelo de anticipación-racional moderno, desde algunos defectos de su aplicación, como lo plantea nuestro autor.

Así, "el otro generalizado" es el fundamento universal de una acción social e institucional en la que "el otro concreto" solo sirve de límite a los peligros de abstracción de la anticipación racional. Según Herrera Flores:

por territorio en los pueblos originarios deben permanecer en el ámbito que les corresponde; es

decir, la especificidad cultural y política de la reivindicación de un espacio vital de vivencia y respeto del entorno.

Cuando son sumadas a las reivindicaciones campesinas (reforma agraria, etc.), suele invisibilizarse el carácter de la reivindicación indígena para quienes la tierra entraña cosmovisiones particulares, de suyo, distintas de las estrictamente campesinas.

... [necesitamos otro] método interpretativo cuyo material esté formado por los tramos dispares de la experiencia histórica, aunque entrelazados e interdependientes, y sobre todo por aquellos que se encuentran en intersección (Herrera 2005b, nota 15 p. 133).

Pero, para lograrlo, hay que desvincular el sentido de la crítica de las necesidades epistemológicas de una teoría apriorística de la racionalidad. Parafraseando a Nancy Fraser, dirá que "necesitamos una crítica social sin anticipaciones racionales abstractas; una intersección real entre el mundo de la teoría y el de las prácticas sociales". 


\section{Conclusiones}

La condición de interseccionalidad como expresión de la complejidad humana permite-en el caso de estas mujeres- mostrar, además, que si la realidad social está cargada de una red de violencias sistemáticas en general entonces traduce la trama dominante del sistema patriarcal y, en particular, deja ver también la serie de micropolíticas horizontales mediante las cuales la fórmula patriarcal realiza alianzas cotidianas de dominación, legitimación y explotación.

Lo descrito apunta, asimismo, a no obviar el orden implicado (replegado) detrás de las estructuras de poder, al momento de pensar o repensar temas como las espiritualidades. Mientras que teológicamente cierta tradición de pensamiento ha definido la espiritualidad desde cierta "pureza" vinculada a interpretaciones apegadas a libros consagrados, desde una Teología Profana la propuesta sería repensar las espiritualidades desde la "impureza" de las interseccionalidades complejas que nos atraviesan a los seres humanos, como se puede destacar en el caso ejemplar de las autobiografías de mujeres mesoamericanas.

En ese marco las violencias interseccionales padecidas por las mujeres mesoamericanas figuran como una cara de la moneda y sus espiritualidades particulares (impuras) aparecen en la otra cara: la realidad bio-psico-corporal de las mujeres evita la reducción de su espiritualidad desde el "a priori" del pensamiento "puro"; como si las violencias de las que es víctima fueran acciones de orden sobrenatural, que irrumpen trastornando su orden natural.

Ordenando estas reflexiones finales, a partir de los aspectos centrales de lo expuesto, procederemos a exponer sus aportes en tres niveles distintos y complementarios:

\section{Narraciones versus discursos: contra la dicotomía teoría-práctica}

a) ¿Cómo, según la lógica de nuestro discurso, deberíamos conjurar estas invisibilizaciones de la realidad desde prácticas de acompañamiento de sectores subalternos?

Desde una posición teórica contra-hegemónica, temáticas como la de la paridad democrática inclusiva, a favor de las mujeres en sociedades asimétricas, puede repensarse como proceso constituyente capaz de potenciar procesos de "intervención ideológica" (Stuart Hall) de lucha contra dominaciones de clase, de género o de etnia.

Herrera Flores (2005b, 164-165) lo expresa recordando que cabría autogenerar producción de textos (historias de vida, testimoniales, literarios, políticos, ensayísticos, etc.), cuyas condiciones de producción fuesen vertientes que reflejen las posiciones/situaciones de sujetos humanos oprimidos $\mathrm{y}$, asimismo, sus propios objetos de referencia, expresamente presentados. Esto es que se produzcan/recopilen narrativas como base empírica investigativaque 
funcionen también como instrumentos de creación e institución constante de la realidad vivida y por vivir; ${ }^{6}$ se trata de una comprensión de la producción creadora del ser humano que proyecte la realidad en su diversidad, gracias a las múltiples percepciones-versiones que tenemos de ella, a partir de los múltiples contextos desde los cuales está situadas las personas y grupos.

Con ello, el autor subraya que lo importante no es anular las diferencias emergentes en las realidad sino estar atentos a ellas en los textos que dan cuenta de ellas; esto hace de las versiones sobre la realidad no entidades fijas o estables sino procesos y productos de relaciones contingentes en que acontece la vida y que cambian de una práctica a otra: por ejemplo, lo que se considera diferencia en una relación determinada (el sexo) no funciona como tal en otra (política o laboral).

Al no haber un tipo homogéneo de diferencia, la narración que nos habla de ella "crea el objeto de referencia" y nos pone ante el conjunto complejo de relaciones en las vivimos o viven nuestro sujeto; bajo un discurso legitimador o no de una situación específica de poder. Es, en consecuencia, un efecto de madurez cultural aceptar que existen múltiples formas de lecto/escritura espiritual (y política) de la realidad que fundamenta dicha realidad en experiencias y prácticas sociales concretas de sujetas/sujetos vivientes contemporáneos cuya voz no solo es rescatable para la investigación social, sino también puede ser pauta para una nueva lectura/escritura de la realidad social.

Epistemológicamente, esta potencial lecto/escritura de base expresará que existe una relación de fondo -dialéctica-entre el "otro generalizado" (la teoría) y el "otro concreto" (la práctica): emerge así una interrogante, ¿qué oportunidad tendría semejante aproximación analítica para pensar separadamente la teoría de la práctica?

Herrera Flores denomina esta tendencia como un dualismo esencialmente funcional al "depredador patriarcal" (2005a, 165-166) aludiendo al contenido que Pinkola (2008) le atribuye (visión-de-mundo) porque demuestra toda su fuerza en los discursos monolíticos y ciegos a las diferencias, en tanto relaciones en las que nos mueve el régimen del patriarcado en que existimos.

b) Debate entorno del "mejor argumento" como cumbre de la racionalidad moderna

De entrada, a propósito de las cosmovisiones presentes en el discurso de los derechos humanos políticos de las mujeres, algo nos advierte tener cuidado si estamos fundamentados en una suerte de "anticipación-racional-moderna" (Herrera 2005b) para colocarnos en posición-corporal-espiritual "interseccional" al preguntarnos por lo que vertebra la acción: porque la justificación de la democracia o del respeto a los derechos humanos, en nombre de la mera consecuencia, eminentemente teórica, de que triunfe "el mejor argumento" (el más lúcido o justo dentro del marco de una democracia deliberativa idealizada), resulta patológico, si se ignora que en los puntos de partida de los participantes en semejante competencia las condiciones existentes son injusta-

6. En esta tesitura se mueven por ejemplo las historias de vida producidas por el Centro de Comunicación Voces Nuestras que nos ha facilitado el material recopilado por ellas desde el año 2002 hasta el 2013 a lo largo y ancho de Mesoamérica. Centro de Comunicación Educativa VOCES NUESTRAS. Manual Apropiándonos de Nuestra Vida. Ed. Voces Nuestras. San José. Accesible en: http://www.vocesnuestras.org/ documento/guia-apropiandonosnuestra-vida

http://www.vocesnuestras.org/li bros

WEB. Accesible en:

http://www.vocesnuestras.org/ quienes-somos 
mente desiguales. En la vida efectiva de las mujeres de la región mesoamericana, debajo del problema de sus derechos humanos políticos incluso como buen argumento de una democracia radicalestá "agazapada" la desigualdad fundamental: la de género que es toda una gran puerta de bienvenida a una serie reticular de otras violencias.

Es así que el origen discursivo de la justificación deliberativa de la democracia (Herrera 2005b, 153-154), puede caerse a partir de su soporte en la creencia (aceptación a priori) de unas condiciones ideales de deliberación, al margen de los contextos reales en los que están situadas las mujeres.

Se trata, así, de una percepción-concepción de democracia abstracta, cuyo contenido principal es procedimental: se decide previamente que los mecanismos formales de la representación equivalen a los de un régimen democrático universalmente válido, al margen de espacio-tiempo, y que sus relaciones deliberativas marcarán per seel ritmo del avance democrático.

Con este tipo de justificaciones se establecen las bases para la generalización de un tipo de ciudadanía ciega ante diferentes contextos en la que están situados actores/as que deliberan; esconde, según Herrera Flores, una reticencia fuerte a la inclusión de "otras voces, otras miradas y otras percepciones culturales" (Herrera, 2005b, 154-155). Adelante, veremos cómo el modelo de análisis de interseccionalidad ofrece un punto de partida más realista que el de "anticipación-racional-moderna", en el sentido de que de acepta que la realidad a analizar tiene más de compleja que de predecible.

Para efectos prácticos, la aplicación abstracta procedimental deja así a merced de un mecanismo automáticola legitimación de supuestas representatividades impuestas al orden social real fundado en estructuras múltiples y contradictorias. Tal orden, articulado, de diferenciación y subordinación en múltiples planos: raza, orientación sexual, pertenencia étnica y de clase, etc. Dichos niveles se oponen de plano a los términos "a priori" en los que la "deliberación" sustenta el debate democrático. Este ideal de ciudadanía abstraído, además de extender a todas las personas su contenido, tiene dos componentes semánticos adicionales:

- $\quad$ por una parte, dicha universalidad funciona desde lo que, supone, tienen en común todos los ciudadanos (no de aquello que los diferencia) y por otra,

- al operar, desde esta ideología dominante, convierte la universalidad en un conjunto de reglas y leyes iguales para todos y aplicables por igual a todas las personas sin detenerse a estimar diferencias individuales o grupales (Herrera 2005b, 154-155).

Los conceptos genéricos como pueblo, nación, población, consumidores y, el más extendido, "ciudadanos" son entidades abstractas en las que no se aprecian diferencias. Las relaciones sociales de clase o segregación racial o étnica, de colonización de las formas de vida antagonista al orden dominante, se difuminan e invisibilizan justificando, quizá, a pesar de los objetivos deliberacionistas, el proyecto social de dominio y explotación que han representado 
históricamente los modos de producción basados en la acumulación capitalista (Herrera, 2005b,155).

Para Herrera, obviando que la idea de ciudadanía puede aportar argumentos válidos para el debate, por sus usos ostenta contornos específicos de género, raza, clase y sexualidad particulares que contaminan las mismas posibilidades de argumentación racional: para el autor se trata de ofrecer cuestionamientos directos al argumento básico de democracia deliberativa, tal como ha sido utilizado y argumentado.

El "mejor argumento" supone entonces "sujetos en condiciones idealmente idénticas", pero se trata de un tipo de racionalidad que surge en el ámbito de la burguesía revolucionaria del siglo XIX (blanca, propietaria privada, cristiana y masculina) y que se presenta como universal; es decir, ajena a los presupuestos e intereses de esa clase social: ¿cómo podría no estar asociado el "mejor argumento" con lo que le interesa a la clase dominante y el peor argumento con lo que es útil a la clase, al sexo o a la etnia subordinadas?

El mismo escenario de que el "mejor argumento" se basa en la maximización de la competitividad entre los argumentos de modo que el mejor consiga derrotar al adversario, ¿qué hacer con aquellos puntos de vista que no se dejan imponer tal escenario y pretenden ofrecerse como un punto de vista más sin pretensión de vencer a otros? Parece que son condenados a quedarse en lo doméstico para que no ofendan la sensibilidad profesional de quienes son "verdaderos argumentadores" (Herrera 2005b,156-157).

c) Recuperación de la espiritualidad y su carácter emancipatorio en las luchas de las mujeres

No es serio que estos argumentadores/argumentaciones quisieran que todo lo que se les opone es contrario a la democracia: la naturaleza misma de lo que hemos denominado "espiritualidad" contiene una reserva fundamental de pensamiento crítico; es decir, apela a esa capacidad intrínseca del espíritu humano de idear lecturas y acciones alternativas de autotrascendencia, de modo que lo dado, lo admitido como verdadero, justo y bello, siempre está en la palestra de la discusión y revisión según el grado en que contribuye, al menos, a que retroceda todo lo que produce degradación y dolor innecesariopor ello injusto en la vida cotidiana y estructuras de poder sociocultural.

Y es que las propuestas deliberativas inclusivas de la visión política de las mujeresdeberían caber los argumentos basados en sus emociones y en sus referencias corporales y comunitarias y no solamente aquellas que toman como únicamente valioso el tipo de argumento circular en que unas premisas que anticipan racionalmente (modernamente) algunas verdades, fijan la coherencia con relación a la conclusión a la que puede arribarse. Porque la trampa de la dualidad mente-cuerpo sigue sosteniendo como verdad el único y sin alternativa sistema de relaciones sociales en el marco del patriarcado, el sexismo, el clasismo y toda suerte de racismos. 
De este modo como tantas veces quiere dejar fuera del debate aquellos argumentos (razonables) de las mujeres y les recrimina estar basados en sentimientos, afectividades, sueños, deseos, etc. según en la diferencia sexual o étnica, tanto en lo laboral como en el ámbito doméstico. Avtar Brah (Herrera 2005b,157, nota 36) identifica cuatro formas bajo las cuales se dan esas diferencias relativizando con ello todo presupuesto procedimental y homogéneo:

- La diferencia como "experiencia cotidiana".

- La diferencia como "relación social", producto de genealogías y narraciones colectivas sedimentadas con el tiempo.

- Las diferencias como "posiciones de sujeto" o de "subjetividad" surgidas frente a la idea de un sujeto político moderno universal o de un Yo unitario, centrado, racional.

- Y, por último, la diferencia como "proceso de subjetivación" o de toma de conciencia de la necesidad de luchar por la dignidad humana de todas y de todos.

Cualquier proclamación de una identidad colectiva homogénea es relativizada por el reconocimiento de estos niveles de diferencia que deberían ser considerados como elementos previos, que condicionan los argumentos de unos y de otras desde las fronteras. Herrera Flores suma a la crítica, una confrontación al modelo de la anticipación-racional-moderna: "el hecho con el que convivimos es el de la diferencia y no el de la homogeneidad cerrada que permite pasar sin transición ideológica de las premisas a las conclusiones como si fuera un proceso natural", nos indica Herrera Flores.

¿Qué podría hacer una feminista negra, una mujer burguesa y una mujer chicana en el caso de que fueran admitidas al debate en una discusión fundamentada en los procesos deliberativos ideales empeñados en garantizar consensos desde la perspectiva del mejor argumento?

¿Tendrán oportunidad de que su punto de vista sea escuchado en un foro montado sobre el principio de igualdad formal que invisibiliza las condiciones estructurales que marcan esos puntos de vista?

La trascendencia de corte abstracto-universal obliga a ofrecer argumentaciones que trasciendan las condiciones contextuales mediante una estrategia de lenguaje-válido para el debate, que ignora las condiciones "interseccionales" por las cuales una mujer o un grupo de ellas, prefieren elegir los frentes de discusión, conforme a los flancos mejor vulnerables en cada caso. El riesgo de desproteger algunas áreas de la vida (especialmente las más cercanas a la dinámica cotidiana y a las opresiones ligadas a ella) hace que las mujeres cuya experiencia de auto-trascendencia estriba en la ruptura con el orden patriarcal, difícilmente entiendan los escenarios que el modelo de anticipación racional, como un marco para deliberar, plantea. 
El foco del debate para el feminismo crítico está, precisamente, anclado en la diferencia interseccional más significativa que marca un punto diferenciador de las identidades convocadas al debate. Y la crítica al problema básico de una deliberación diseñada con ese postulado, apunta a dos presuposiciones no confesadas por el modelo de anticipación racional moderna: o bien este presupone un consenso previo sobre premisas que no se consideran premisas, sino elementos naturalmente universales; o bien, tal unidad se ve como la meta final a la que necesariamente ha de llegarse por la fuerza de sometimiento de otros ante los propios argumentos de dicho modelo de anticipación racional: ¿estaremos acá ante la consolidación de nuevas exclusiones bajo las intenciones "buenas" de acogerse al "mejor argumento" como ruta para las decisiones? Más opresiones o nuevas exclusiones, ¿cómo podrían ser un buen resultado de una política deliberativa sobre las necesidades humanas y los derechos de las mujeres prescindiendo de lo que interseccionalmente da las pautas estratégicas de exposición en el ámbito público?

\section{Bibliografía}

Gilligan, Carol. 1985. La moral y la teoría: psicología del desarrollo femenino. México: FCE.

Guerra, María José. 2001. Teoría feminista contemporánea. Una aproximación a la ética. Instituto de Investigaciones Feministas. Universidad Complutense de Madrid.

Herrera, Joaquín. 2005a De habitaciones propias y otros espacios negados: una teoría crítica de las opresiones patriarcales. Bilbao: Universidad de Deusto.

Herrera, Joaquín. 2005b. Los Derechos Humanos como productos culturales. Crítica del humanismo abstracto. Madrid: Libros de la Catarata.

Gandarias, Itzar. 2012. "Posibilidades y limitaciones del concepto de interseccionalidad". Barcelona: Ponencia en Simposio Universidad Autónoma de Barcelona. Acceso en: https://www.academia.edu/2444612/Posibilidades_y_limitaciones_del_c oncepto_de_interseccionalidad_como_herramienta_de_an

\%C3\%A1lisis_y_acci\%C3\%B3n_pol\%C3\%ADtica_feminista 
Möller, Susan. 1996. Desigualdad de género y diferencias culturales, en: Perspectivas feministas en teoría política. Paidós: Barcelona.

Pinkola Estes, Clarissa. 2008. Mujeres que corren con los lobos. ZETA: Barcelona.

Wolf Virginia. 2008 Una habitación propia. Seix Barral: Barcelona. 